\title{
Efeitos dos níveis de extrato etéreo no sucedâneo do leite sobre o desenvolvimento corporal de bezerros Jersey 1
}

\author{
Marta Farias Aita ${ }^{2}$, Vivian Fischer ${ }^{3}$, Waldyr Stumpf Jr. ${ }^{4}$
}

\author{
${ }^{1}$ Dissertação de Mestrado do primeiro autor, com apoio financeiro da Embrapa Clima Temperado, da AVIPAL e do PPGZ/UFPEL. \\ 2 Pós-graduação em Zootecnia, UFPEL - Pelotas - RS, bolsista CAPES. \\ ${ }^{3}$ Departamento de Zootecnia, Faculdade de Agronomia - UFRGS-Porto Alegre-RS, Professora Convidada do PPGZ-UFPEL - Pelotas - RS. \\ Bolsista do CNPq. \\ ${ }^{4}$ Embrapa Clima Temperado-Pelotas-RS.
}

\begin{abstract}
RESUMO - Utilizaram-se 20 bezerros Jersey com o objetivo de avaliar o efeito dos níveis de extrato etéreo no sucedâneo comercial sobre o peso corporal, o ganho de peso médio diário, a altura na cernelha, o perímetro torácico e o consumo de concentrado, do 8 o ao $90^{\circ}$ dia de idade, visando determinar o melhor nível de extrato etéreo. Os animais foram distribuídos nos tratamentos, que consistiram de quatro dietas líquidas: leite integral $\left(\mathrm{T}_{1}\right)$, sucedâneo lácteo comercial padronizado com gordura suína para $10\left(\mathrm{~T}_{2}\right), 15\left(\mathrm{~T}_{3}\right)$ e $20 \%\left(\mathrm{~T}_{4}\right)$ de extrato etéreo (EE) na matéria seca, de acordo com a seqüência de nascimento. O delineamento experimental utilizado foi o de blocos ao acaso com arranjo fatorial desbalanceado, em que os fatores foram a dieta $(n=4)$ e o sexo $(n=2)$. Os dados de desenvolvimento corporal e consumo de alimento foram submetidos à análise de variância. Aos 56 dias de idade, os bezerros alimentados com leite integral e sucedâneo a 10\% EE apresentaram diferença significativa no peso corporal e no ganho de peso médio diário (8-56 dias). Os bezerros que receberam leite integral apresentaram maior perímetro torácico e, após o desaleitamento, medidas de peso corporal, ganhos de peso médio diário (57 a 89 dias), perímetro torácico e altura na cernelha superiores às dos que receberam o sucedâneo. Na fase de aleitamento, o sucedâneo a $10 \%$ EE promoveu ganho de peso superior ao sucedâneo a 15 e $20 \%$ de EE na matéria seca e ganho de peso similar ao leite integral.
\end{abstract}

Palavras-chave: altura na cernelha, desaleitamento, perímetro torácico, peso corporal

\section{Effects of different ether extract levels of a milk replacer on body development of Jersey calves}

\begin{abstract}
Twenty Jersey calves were used to investigate the effects of different ether extract levels of a commercial milk replacer on body weight, average daily weight gain, height at withers, heart girth, and starter intake from the $8^{\text {th }}$ to the $90^{\text {th }}$ day after birth. It was of particular interest to determine the optimum milk replacer ether extract level. This trial was conducted at EMBRAPA Clima Temperado, CPACT, from October 2000 to May 2001. Animals were assigned, according to their birth date, to one of four liquid diets as follows: whole milk (T1) or milk replacer plus different proportions of lard to yield 10 (T2), 15 (T3) or 20\% (T4) ether extract on dry matter basis. Statistical analysis was performed as a randomized complete block design with an unbalanced factorial arrangement and diets $(n=4)$ and sex $(n=2)$ as factors. Data from body development and starter intake were both submitted to analysis of variance. Body weight at 56 days of age and average daily weight gain from eight to 56 days post-calving were significantly higher for animals receiving $\mathrm{T} 1$ and $\mathrm{T} 2$ than for those fed $\mathrm{T} 3$ and $\mathrm{T} 4$ liquid diets. In addition, heart girth at 56 days of age was greater on calves fed whole milk than on those fed milk replacer with different proportions of lard. After weaning, calves on T1 diet had increased body weight, average daily weight gain (57-89 days), heart girth, and height at withers compared to calves on milk replacer diets. In the weaning phase, feeding T2 to calves resulted in higher body weight gain than those fed T3 and T4 diets while no difference was observed comparing T2 andT1.
\end{abstract}

Key Words: body weight, heart girth, height at withers, weaning

\section{Introdução}

A pecuária leiteira é um dos segmentos mais importantes do setor agropecuário do Rio Grande do Sul. Além de envolver grande número de produtores, é desenvolvida em $80 \%$ dos municípios gaúchos e resulta na produção de um alimento essencial à dieta humana (Bitencourt et al., 2000).

A alimentação é o item que mais onera a criação de bezerros, principalmente nos primeiros meses de vida, quando o leite é o principal alimento. Como alternativas para redução desse custo, sem prejudicar o desenvolvimento 
dos bezerros, recomenda-se a utilização de colostro excedente e de quantidades limitadas de dieta líquida, o desaleitamento precoce e o fornecimento de concentrado a partir da segunda semana de idade (Campos, 2005).

Bezerros recém-nascidos possuem pouca reserva corporal de gordura, alta exigência energética e pêlos curtos. A ingestão de energia da dieta pode ser melhorada com incremento da densidade energética, aumento da quantidade fornecida de leite ou de sucedâneo lácteo, aumento da ingestão de matéria seca da dieta líquida (12 a 15\% de sólidos), fornecimento de um concentrado inicial peletizado à base de produtos lácteos, uso de gordura suplementar na dieta líquida ( 10 a $20 \%)$ ou estímulo ao consumo precoce de alimentos sólidos (Hutjens, 2002; Coverdale, 2005; Dairy Connection, 1998).

Baixas temperaturas e altas precipitações pluviométricas, adicionadas ao estresse, podem reduzir fortemente as taxas de crescimento desses animais. Estes fatores aumentam a necessidade de energia para manutenção da temperatura corporal, disponibilizando menos energia para o crescimento ou para capacidade imune (Dairy Connection, 1998).

Diversos estudos têm sido realizados com o objetivo de discutir a utilização do sucedâneo lácteo e apresentar possibilidades e alternativas para a formulação dessas dietas líquidas para bezerros (Alvarez et al., 1999; Azambuja, 1980; Campos et al., 1981; Ferreira, 1996; Peixoto, 1982; Roy, 1972; Susin et al., 1988).

Suplementos de gordura são freqüentemente adicionados a dietas visando aumentar a densidade energética, melhorar a absorção de vitaminas lipossolúveis, diminuir a incidência e a severidade de diarréias, reduzir o estresse e auxiliar na redução da poeira do alimento (Holstein Foundation, 2003; Quigley, 2001).

No passado, a maioria dos sucedâneos disponíveis no mercado apresentava em sua formulação $10 \%$ de gordura. Atualmente, os sucedâneos formulados com $20 \%$ de gordura dominam o mercado americano em detrimento àqueles com 15 e $20 \%$ de gordura, que praticamente não são comercializados (Quigley, 2001).

Existem várias opções para aumentar o nível de gordura no sucedâneo lácteo, incluindo o sebo, uma gordura relativamente pouco aproveitada pelo animal, em razão da presença dos ácidos graxos saturados esteárico e palmítico, de menor digestibilidade. Para melhorar sua digestibilidade, recomenda-se a inclusão de lecitina de soja ( 1 a $6 \%$ na matéria seca) e sua homogeneização. A lecitina de soja atua como emulsificante e fonte de fosfolipídeos. O óleo de coco também pode ser utilizado para melhorar a digestibilidade do sebo, pois fornece ácido graxo de cadeia curta (Roy, 1972).

Outra alternativa seria o uso da gordura suína, que apresenta em sua composição os ácidos graxos oléico (42\%), palmítico (28\%), esteárico (15\%), linoléico (9\%), palmitoléico (3\%), linolênico (2\%) e merístico (1\%) (Byers $\&$ Schelling, 1993).

O‘Brien et al. (2003) pesquisaram a utilização da gordura vegetal em substituição à gordura animal na formulação de sucedâneos lácteos e concluíram que a gordura vegetal pode ser uma fonte de gordura alternativa eficiente na composição dos sucedâneos lácteos. Resultados satisfatórios também foram obtidos com o uso exclusivo de óleos vegetais, como os de soja, de palma e de coco. Entretanto, os óleos vegetais apresentam custo maior que a gordura animal (Costello, 2005).

A incorporação de gordura ao sucedâneo do leite deve ser feita de modo que as partículas de gordura não ultrapassem 3 a $4 \mu$ de diâmetro no sucedâneo reconstituído, sob pena de provocar distúrbios digestivos (diarréias) e alopecia durante as primeiras três semanas de vida. A alopecia, caracterizada pela queda de pêlos nas orelhas e no pescoço e, posteriormente, na perna e nas extremidades posteriores, pode ocorrer quando a dieta contém gordura mal homogenizada ou óleos de algodão, de soja ou de milho (Roy, 1972).

Ao utilizar o método de incorporação de gordura a seco deve-se dar preferência a gorduras com alta digestibilidade. Quando esta adição é feita no leite reconstituído, obtêm-se resultados satisfatórios com produtos mais baratos, como o sebo (Roy, 1972).

Neste trabalho, objetivou-se avaliar o desenvolvimento corporal de bezerros da raça Jersey, do $8^{\circ}$ ao $90^{\circ}$ dia de idade, alimentados com sucedâneo lácteo contendo diferentes níveis de extrato etéreo e determinar o melhor nível de inclusão deste nutriente no sucedâneo.

\section{Material e Métodos}

O experimento foi conduzido no período de outubro de 2000 a maio de 2001 no Sistema de Pecuária de Leite (SISPEL), pertencente à Estação Experimental de Terras Baixas do Centro de Pesquisa Agropecuária da EMBRAPA Clima Temperado (CPACT), localizado no município do Capão do Leão, Rio Grande do Sul - RS.

Foram utilizados 20 bezerros ( 11 machos e 9 fêmeas) da raça Jersey, puros de origem, com peso inicial de 27,5 $\mathrm{kg} \pm 3,0$ e coeficiente de variação de 10,91.

Os animais receberam dietas líquidas compostas por leite integral ou sucedâneo com 10, 15 ou $20 \%$ de extrato etéreo na matéria seca.

Para padronização do extrato etéreo a 10,15 e $20 \%$, 
foram adicionados a cada $100 \mathrm{~g}$ de sucedâneo lácteo fornecido 1,87; 6,90 e 11,92 g de gordura suína, respectivamente. Após a análise química do sucedâneo, os níveis de extrato etéreo na matéria seca foram ligeiramente superiores $(11,26$; $16,26$ e $21,26 \%)$ aos esperados $(10,15$ e $20 \%)$ no início do experimento.

Os bezerros permaneceram com as mães durante 72 horas para ingerir o colostro e depois foram transferidos para abrigos individuais. O leite integral foi fornecido a todos os bezerros do $4^{\circ}$ ao $7^{0} \underline{0}$ dia de idade, na quantidade de $2 \mathrm{~L} /$ dia (1 litro/manhã e 1 litro/tarde), perfazendo um total de $8 \mathrm{~L}$ /animal no período.

No oitavo dia, os bezerros foram alocados às dietas experimentais. A partir do oitavo dia de idade, foi ministrada, pela manhã, pequena quantidade de concentrado comercial peletizado $(0,15 \mathrm{~kg})$ de, no máximo, $2 \mathrm{~kg}$ diários/ animal, além do feno de alfafa (Medicago sativa), ad libitum.

Os bezerros receberam diariamente do $8^{\circ}$ ao 29 o dia de idade, em baldes plásticos, $3 \mathrm{~L}$ da dieta líquida, divididos em duas vezes ao dia. Entre o $30^{\circ}$ e $56^{\circ}$ dia de vida, foram fornecidos $3 \mathrm{~L}$ da dieta líquida uma vez ao dia, pela manhã, totalizando 147 litros/animal. Os sucedâneos foram diluídos à razão de $100 \mathrm{~g}$ por litro de água aquecida a $37^{\circ} \mathrm{C} \mathrm{e}$ homogeneizados manualmente. A água foi fornecida, à vontade, uma hora após o fornecimento da dieta líquida. $\mathrm{O}$ desaleitamento foi imposto abruptamente no $56^{\circ}$ dia de idade dos animais.

Entre o $57^{\circ}$ e $90^{\circ}$ dia de idade, os bezerros permaneceram nos abrigos individuais e receberam até $2 \mathrm{~kg}$ de concentrado comercial peletizado e feno de alfafa ad libitum.

No $3 \stackrel{\circ}{\circ}, 8^{\circ}, 56^{\circ}$ e $90^{\circ}$ dias de idade, antes da primeira refeição, pesaram-se os animais e mediram-se a altura na cernelha com a bengala de Thomas e o perímetro torácico, com fita métrica. As medidas foram repetidas semanalmente durante todo o experimento. Além disso, registrou-se diariamente o consumo da dieta líquida e do concentrado comercial e calculou-se, a partir destes valores, a conversão alimentar aparente (consumo de dieta líquida + consumo de concentrado em $\mathrm{kg}$ de matéria seca/ganho em $\mathrm{kg}$ de peso).

O leite integral foi proveniente do rebanho da raça Jersey pertencente à EMBRAPA. O sucedâneo lácteo comercial foi composto de soro em pó, leite em pó desnatado, leite em pó integral, farelo de milho, sais minerais e vitaminas.

O concentrado comercial peletizado foi composto basicamente por farelo de soja, farelo de arroz desengordurado, farelo de trigo, milho integral moído, melaço, remoído de trigo, promotor do crescimento, cloreto de sódio, calcário calcítico e premix mineral e vitamínico.

As amostras de leite integral foram coletadas mensalmente do tanque resfriador, após a ordenha da tarde, acondicionadas em caixa de isopor com gelo para análises químicas e processadas no dia posterior à coleta.

Semanalmente, foram coletadas as amostras do sucedâneo lácteo comercial, do concentrado peletizado comercial e do feno de alfafa, posteriormente misturadas para formação de uma amostra composta mensal. Das amostras compostas foram retiradas alíquotas, destinadas às análises químicas. Os valores médios obtidos nas análises químicas do sucedâneo lácteo, do feno de alfafa, do leite integral e do concentrado comercial encontram-se na Tabela 1.

O delineamento experimental utilizado foi o de blocos ao acaso, em arranjo fatorial desbalanceado, considerando-se os fatores blocos $(n=5)$, dietas líquidas $(n=4)$ e $\operatorname{sexo}(n=2)$ com os tratamentos distribuídos de acordo com a ordem de nascimento dos animais.

Os dados referentes ao peso corporal, à altura na cernelha, ao perímetro torácico, avaliados aos $56^{\circ} \mathrm{e}$ e $90^{\circ}$ dias, o ganho de peso médio diário, e o consumo de concentrado na fase de aleitamento ( $8^{\circ}$ a $56^{\circ}$ dias) e após o desaleitamento ( $57^{\circ}$ a $89^{\circ}$ dias) e o consumo total de concentrado ( $8^{\circ}$ a $89^{\circ}$ dias) foram submetidos à análise de variância. Foram considerados os fatores dieta líquida, sexo e bloco e o peso ao 8 o dia como covariável. As médias foram ajustadas e comparadas segundo Lsmeans (DMS de Fisher), a 5\% de significância. Foram

Tabela 1 - Valores médios (\% de matéria seca) da composição química do leite integral, do sucedâneo lácteo, do concentrado comercial peletizado e do feno de alfafa

Table 1 - Cchemical composition of whole milk, milk replacer, commercial concentrate, alfalfa hay (Medicago sativa), dry matter \%

\begin{tabular}{|c|c|c|c|c|}
\hline $\begin{array}{l}\text { Item } \\
\text { Item }\end{array}$ & $\begin{array}{c}\text { Feno de alfafa } \\
\text { Alfalfa hay }\end{array}$ & $\begin{array}{c}\text { Concentrado } \\
\text { Concentrate }\end{array}$ & $\begin{array}{c}\text { Sucedâneo lácteo } \\
\text { Milk replacer }\end{array}$ & $\begin{array}{c}\text { Leite integral } \\
\text { Whole milk }\end{array}$ \\
\hline Matéria seca (Dry matter) & 89,99 & 92,14 & 90,86 & 13,69 \\
\hline Extrato seco desengordurado (Solids non fat) & - & - & - & 9,56 \\
\hline Cinzas (Ash) & 11,81 & 7,64 & 7,29 & - \\
\hline Proteína bruta (Crude protein) & 20,98 & 20,45 & 23,08 & 24,31 \\
\hline Extrato etéreo (Ether extract) & 1,60 & 2,57 & 9,40 & 30,20 \\
\hline FDN $(N D F)$ & 60,80 & 39,44 & 4,04 & - \\
\hline $\mathrm{FDA}(A D F)$ & 45,35 & 11,79 & - & - \\
\hline
\end{tabular}


avaliados os efeitos do nível de gordura na dieta líquida, do consumo de concentrado e do peso inicial ( 8 - dia) po rmeio da regressão, utilizando-se o procedimento reg opção stepwise do programa estatístico SAS versão 6.12 (SAS, 1989).

\section{Resultados e Discussão}

Os valores médios de peso corporal, perímetro torácico e altura na cernelha ao $56^{\circ}$ (desaleitamento) e ao $90^{\circ}$ dias (final do experimento) de idade dos bezerros, o ganho de peso médio diário do $8^{\circ}$ ao $56^{\circ}$ dia (período de aleitamento) e do $57^{\circ}$ ao $89^{\circ}$ dia de idade e o consumo de concentrado nas diferentes fases do experimento estão apresentados nas Tabelas 2 e 3 .

O peso dos bezerros aos 56 dias de idade variou significativamente entre as dietas líquidas $(\mathrm{P}=0,0070)$. Os animais que receberam o leite integral e o sucedâneo lácteo com $10 \%$ de EE apresentaram os maiores pesos corporais, o que poderia ser explicado pela maior concentração de energia no leite - reflexo de seu elevado teor de gordura, que permite maior ingestão de energia - e pelo maior consumo de concentrado pelos animais que receberam a dieta com $10 \%$ EE, com a finalidade de compensar o baixo nível energético desta dieta líquida.

Neste período, os bezerros que receberam o sucedâneo com 15 ou $20 \%$ de EE e leite integral consumiram em média menos 7,39; 8,22; e 17,77 kg, respectivamente, de concentrado em relação aos que receberam o sucedâneo lácteo com $10 \%$ de $\mathrm{EE}$, demonstrando decréscimo linear no consumo à medida que o nível de gordura aumentou $(\mathrm{P}=0,0327)$.

Bezerros que consomem mais energia proveniente da dieta líquida necessitam de menor aporte de energia do concentrado e tendem a reduzir o consumo de concentrando, iniciando o consumo mais tarde que os alimentados com dieta líquida de menor teor energético. Conseqüentemente, podem sofrer atraso no desenvolvimento ruminal e no desaleitamento (Dairy Connection, 1998; Lucci, 1989; Quigley, 2001).

Outros autores também encontraram resultados inferiores para o consumo de concentrado na fase de aleitamento de bezerros que receberam o leite integral em relação aos que consumiram o sucedâneo (Gomes \& Peixoto, 1982; Matos et al., 1984; Susin et al., 1988; Vasconcelos et al., 1998).

Segundo Drackley et al. (2002), Hutjens (2002), Kuehn et al. (1994), Tikofsky etal. (2001) e Dairy Connection(1998), o fornecimento de gordura adicional (altos níveis de gordura ou alteração na relação energia e proteína) no sucedâneo lácteo tende a reduzir o consumo de concentrado.

No entanto, Silva et al. (1977) não observaram efeito positivo do sucedâneo à base de leite em pó desnatado acrescido de gordura do leite ou de gordura de soja hidrogenada sobre o consumo de concentrado na fase de aleitamento.

Drackley et al. (2002) testaram, em bezerros Jersey, o aumento da concentração de sólidos totais (12,5 e 15,5\%) e a suplementação com gordura no sucedâneo lácteo. Nenhum

Tabela 2 - Médias de peso corporal, ganho de peso médio diário (GPMD), altura na cernelha, perímetro torácico e consumo de concentrado, em kg de matéria seca, no período de aleitamento (CC 8ㅇ ao 56ㅇ dia) de bezerros que receberam leite integral e três níveis crescentes de extrato etéreo (10, 15 e 20\% EE) no sucedâneo lácteo comercial

Table 2 - Means of body weight, average daily weight gain (ADG), height at withers, heart girth, concentrate intake, expressed as kg of dry matter, of pre weaning calves fed whole milk or milk replacer with increasing ether extract levels (10, 15, and $20 \%$ EE)

\begin{tabular}{|c|c|c|c|c|c|c|}
\hline $\begin{array}{l}\text { Variável } \\
\text { Variable }\end{array}$ & $\begin{array}{l}\text { Leite integral } \\
\text { Whole milk }\end{array}$ & $10 \% \mathrm{EE}$ & $15 \% \mathrm{EE}$ & $20 \% \mathrm{EE}$ & $\mathrm{CV}^{1}$ & $\mathrm{R}^{2}$ \\
\hline $\begin{array}{l}\text { Peso ao } 80 \text { dia }(\mathrm{kg}) \\
\text { Weight day at } \text { sth }^{\text {th }} \text { day }(\mathrm{kg})\end{array}$ & $26,50^{\mathrm{a}}$ & $28,05^{\mathrm{a}}$ & $27,60^{\mathrm{a}}$ & $27,70^{\mathrm{a}}$ & 10,91 & - \\
\hline $\begin{array}{l}\text { GPMD } 8^{\circ}-56 \mathrm{v} \text { dia }(\mathrm{kg} / \mathrm{dia}) \\
A D G 8^{\circ}-\text { at } 56^{\text {th }} \text { day }(\mathrm{kg} / \text { day })\end{array}$ & $0,47^{\mathrm{a}}$ & $0,44^{\mathrm{a}}$ & $0,34^{\mathrm{b}}$ & $0,35^{\mathrm{b}}$ & 11,37 & 93,46 \\
\hline $\begin{array}{l}\text { Altura na cernelha ao } 56^{\circ} \text { dia }(\mathrm{cm}) \\
\text { Height at withers day at } 56^{\text {th }} \text { day }(\mathrm{cm})\end{array}$ & $78,64^{\mathrm{a}}$ & $78,25^{\mathrm{a}}$ & $76,39^{a}$ & $77,98^{\mathrm{a}}$ & 1,88 & 77,42 \\
\hline $\begin{array}{l}\text { Perímetro torácico ao } 8^{0} \text { dia }(\mathrm{cm}) \\
\text { Heart girth day at } 8^{\text {th }} \text { day }(\mathrm{cm})\end{array}$ & $70,41^{\mathrm{a}}$ & $69,37^{\mathrm{a}}$ & $69,00^{\mathrm{a}}$ & $70,03^{\mathrm{a}}$ & 1,07 & - \\
\hline $\begin{array}{l}\text { Perímetro torácico ao } 56^{\mathrm{o}} \text { dia }(\mathrm{cm}) \\
\text { Heart girth day at } 56^{\text {th }} \text { day }(\mathrm{cm})\end{array}$ & $84,63^{\mathrm{a}}$ & $81,96^{\mathrm{b}}$ & $79,75^{\mathrm{c}}$ & $80,74^{b c}$ & 1,65 & 91,84 \\
\hline
\end{tabular}

1 Coeficiente de variação (\%) (Coefficient of variation, \%).

${ }^{2}$ Coeficiente de determinação (\%) (Coefficient of determination, \%).

Médias seguidas por letras diferentes na mesma linha diferem $(P<0,05)$ segundo DMS de Fisher.

Means in the same row followed by distinct letters differ $(P<0.05)$ according to $L S D$ Fisher. 
Tabela 3 - Médias de peso corporal, ganho de peso médio diário (GPMD), altura na cernelha, perímetro torácico, consumo de concentrado após o desaleitamento (57-89으 dias) e consumo de concentrado total, em kg de matéria seca (CCT) de bezerros que receberam leite integral e três níveis crescentes de extrato etéreo (10, 15 e 20\% EE) no sucedâneo lácteo comercial

Table 3 - Means of body weight, average daily weight gain (ADG), height at withers, heart girth, and post weaning and total concentrate intakes, expressed as $\mathrm{kg}$ of dry matter for calves fed whole milk or milk replacer with increasing ether extract levels $(10,15$, and $20 \%$ EE)

\begin{tabular}{|c|c|c|c|c|c|c|}
\hline $\begin{array}{l}\text { Variável } \\
\text { Variable }\end{array}$ & $\begin{array}{l}\text { Leite integral } \\
\text { Whole milk }\end{array}$ & $10 \% \mathrm{EE}$ & $15 \% \mathrm{EE}$ & $20 \% \mathrm{EE}$ & $\mathrm{CV}^{1}$ & $\mathrm{R}^{2}$ \\
\hline Peso ao $90^{\circ}$ dia $(\mathrm{kg})$ & & & & & & \\
\hline $\begin{array}{l}\text { Weight at } 90^{\text {th }} \text { day }(\mathrm{kg}) \\
\text { GPMD } 570-890 \text { dia }(\mathrm{kg} / \mathrm{dia})\end{array}$ & $75,74^{\mathrm{a}}$ & $66,90^{\mathrm{b}}$ & $62,70^{\mathrm{b}}$ & $62,55^{\mathrm{b}}$ & 6,35 & 83,92 \\
\hline $\begin{array}{l}A D G 57^{\text {th }}-89^{\text {th }} \text { day }(\mathrm{kg} / \mathrm{day}) \\
\text { Altura na cernelha ao } 90 \mathrm{0} \text { dia }(\mathrm{cm})\end{array}$ & $0,59^{\mathrm{a}}$ & $0,48^{\mathrm{b}}$ & $0,43^{b}$ & $0,43^{\mathrm{b}}$ & 10,81 & 85,90 \\
\hline $\begin{array}{l}\text { Height at withers at } 90^{\text {th }} \text { day }(\mathrm{cm}) \\
\text { Perímetro torácico ao } 90^{\underline{0}} \text { dia }(\mathrm{cm})\end{array}$ & $86,12^{\mathrm{a}}$ & $83,64^{\mathrm{b}}$ & $81,28^{\mathrm{c}}$ & $83,45^{\mathrm{b}}$ & 1,11 & 93,79 \\
\hline $\begin{array}{l}\text { Heart girth at } 90^{\text {th }} \text { day }(\mathrm{cm}) \\
\text { Consumo de concentrado } 570-890 \text { dia }(\mathrm{kg})\end{array}$ & $96,74^{\mathrm{a}}$ & $90,85^{\mathrm{b}}$ & $87,81^{\mathrm{c}}$ & $90,48^{b c}$ & 1,91 & 93,80 \\
\hline Concentrate intake $57^{\text {th }}-89^{\text {th }}$ day day ( $\mathrm{kg}$ ) & $55,56^{\mathrm{a}}$ & $54,16^{\mathrm{a}}$ & $52,07^{\mathrm{a}}$ & $53,20^{\mathrm{a}}$ & 6,89 & 72,75 \\
\hline Consumo de concentrado total $(\mathrm{kg})$ & $68,57^{\mathrm{a}}$ & $84,94^{\mathrm{a}}$ & $75,46^{\mathrm{a}}$ & $75,76^{\mathrm{a}}$ & 11,18 & 81,30 \\
\hline
\end{tabular}

${ }^{1}$ Coeficiente de variação (\%) (Coefficient of variation, \%).

${ }^{2}$ Coeficiente de determinação (\%) (Coefficient of determination, \%).

Médias seguidas por letras diferentes na mesma linha diferem entre si segundo DMS de Fisher $(P<0,05)$.

Means in the same row followed by distinct letters differ $(P<0.05)$ according to LSD Fisher.

dos tratamentos afetou a média de ganho de peso diário, apesar de o consumo de concentrado diminuir com o acréscimo de gordura e de sólidos no sucedâneo.

Os animais que receberam leite integral, apresentaram na fase de aleitamento, melhor conversão alimentar aparente $(1,41 \%)$ que aqueles alimentados com sucedâneo lácteo com $10(2,15 \%), 15(2,27 \%)$ e $20 \%$ (2,16\%) de EE na MS.

Prado \& Tiesenhausen (1982) avaliaram o ganho de peso de bezerros alimentados com três dietas distintas: leite integral, leite de soja e leite de soja $+3 \%$ de gordura suína. O ganho de peso corporal e o consumo de concentrado foram maiores nos animais alimentados com leite integral e menor naqueles que consumiram leite de soja + gordura suína, assim como a conversão alimentar foi mais eficiente com leite integral e pior com leite de soja + gordura suína.

Neste trabalho, não foram constatadas diferenças significativas de peso entre os sexos $(\mathrm{P}=0,7008)$. Os machos apresentaram peso médio de $46,87 \mathrm{~kg}$ e as fêmeas, de $46,40 \mathrm{~kg}$, como observado por Medina et al. (2002).

Foram encontradas diferenças significativas entre as dietas líquidas e o ganho de peso médio diário na fase de aleitamento, $\operatorname{dos} 8$ aos $56 \operatorname{dias}(\mathrm{P}=0,0070)$, sendo a média geral de ganho de peso diário de $0,390 \mathrm{~kg}$. Os ganhos de peso médios diários foram superiores para os animais que receberam leite integral e sucedâneo com $10 \%$ de EE em relação àqueles que ingeriram o sucedâneo com 15 e $20 \%$ de EE. Entretanto, resultados superiores de peso corporal em bezerros alimentados com leite integral foram encontrados por Silva et al. (1987), Vasconcelos et al. (1999) e Medina et al. (2002), em relação àqueles alimentados com sucedâneo.
O sucedâneo lácteo utilizado por Medina et al. (2002) apresentou em sua composição química, $24,55 \%$ de PB e $4,85 \%$ de EE na MS; ou seja, o valor de proteína bruta foi superior ao encontrado neste trabalho $(23,08 \%)$ e o nível de extrato etéreo, inferior. O menor teor energético no sucedâneo utilizado por Medina pode explicar parcialmente o menor ganho de peso dos animais alimentados com o sucedâneo lácteo $(0,32 \mathrm{~kg})$.

Kuehn et al. (1994), ao avaliarem o efeito de um sucedâneo lácteo e de um concentrado com alta $(21,6$ e $7,3 \%$, respectivamente) e baixa $(15,6$ e $3,7 \%$, respectivamente) concentrações de gordura, encontraram, antes do desaleitamento, ganhos de peso corporal menores no sucedâneo com alto teor de gordura, além de consumo de concentrado reduzido durante a fase de aleitamento e após o desaleitamento.

O'Brien et al. (2003) compararam o uso de gordura animal, óleo de palma + óleo de coco e $85 \%$ óleo de soja + $15 \%$ óleo de coco e registraram ganhos de peso inferiores quando os animais foram alimentados com gordura animal no sucedâneo.

Wijayasinghe et al. (1984) forneceram dietas com alto teor de carboidrato e baixo de gordura $(60,5 \%$ glicose + $9,5 \%$ lactose $+3 \%$ gordura suína) e baixo teor de carboidrato e alto de gordura $(23 \%$ glicose $+12,5 \%$ lactose $+30 \%$ gordura suína) e observaram maior ganho de peso corporal e melhor conversão alimentar nos bezerros alimentados com a dieta com maior teor de gordura.

Jaster et al. (1990) testaram a adição de um suplemento de gordura em pó comercial $(0,113 \mathrm{~kg} / \mathrm{dia})$ ao leite integral e ao sucedâneo lácteo. Os ganhos de peso dos 3 aos 28 dias 
de idade foram superiores nos bezerros suplementados com gordura na dieta líquida, com ganho de peso médio diário de 0,$098 ; 0,154 ; 0,120 ;$ e $0,187 \mathrm{~kg}$ para os alimentados com leite integral, leite integral e gordura, sucedâneo lácteo e sucedâneo e gordura, respectivamente. Jaster et al. (1992) também forneceram um sucedâneo lácteo com adição de $0 ; 0,113$; e 0,226 kg de suplemento de gordura comercial e encontraram ganho de peso maior para os alimentados com $0,226 \mathrm{~kg} / \mathrm{dia}$. O consumo de concentrado foi semelhante entre os grupos que receberam 0 e $0,113 \mathrm{~kg}$ de suplemento de gordura, mas foi inferior no grupo suplementado com $0,226 \mathrm{~kg}$.

Hill et al. (2002) utilizaram três tipos de sucedâneo lácteo $(20 \%$ de proteína bruta e $20 \%$ de gordura; $20 \%$ de proteína bruta e $15 \%$ de gordura; e $18 \%$ de proteína bruta e $15 \%$ de gordura) e não encontraram diferença no ganho de peso e no consumo de concentrado.

A altura na cernelha obtida aos 56 dias de idade não apresentou diferença significativa entre os tratamentos ( $\mathrm{P}=0,1871)$, embora bezerros alimentados com leite integral tenham apresentado ligeira superioridade numérica em relação aos que receberam os sucedâneos lácteos com 10,15 e 20\% de EE. Resultados semelhantes foram obtidos por Silva et al. (1977), ao avaliarem a adição de dois tipos de gordura (do leite e da soja hidrogenada) ao sucedâneo lácteo.

O perímetro torácico ao desaleitamento variou significativamente entre os tratamentos $(\mathrm{P}=0,0048)$, resultado diferente dos encontrados por Silva etal. (1977), Banys etal. (1999)e Silva etal.(1987). Os bezerros que consumiram leite integral apresentaram perímetro torácico significativamente superior aodos que receberam o sucedâneo lácteo, ao passo que o perímetro torácico dos animais que ingeriram o sucedâneo com $10 \%$ de EE não foi diferente dos que receberam o sucedâneo com $20 \%$, que, por sua vez, não diferiu dos alimentados com 15\% de EE.

Aos 90 dias de idade, os animais que receberam o leite integral apresentaram peso corporal significativamente superior ( $\mathrm{P}=0,0075)$ ao daqueles que receberam níveis crescentes de gordura no sucedâneo lácteo (Tabela 3). O peso corporal dos bezerros alimentados com leite integral foi semelhante ao encontrado por Heinrichs \& Hargrove (1991). Entretanto, Azambuja (1980) não constatou diferença de peso corporal entre bezerros Holandeses alimentados com leite integral e com dois tipos de sucedâneo.

$\mathrm{Na}$ fase após o desaleitamento, dos 57 aos 89 dias de idade, os animais que receberam o leite integral apresentaram ganhos de peso superiores aos que consumiram o sucedâneo lácteo, o que provavelmente foi resultado do aumento no consumo de concentrado destes animais, além da maior ingestão de energia proveniente do leite durante a fase de aleitamento (Tabela 3 ).
Matos et al. (1984) não detectaram diferenças significativas entre as médias de ganho de peso no período após o desaleitamento ( 57 aos 182 dias) entre os animais alimentados com leite integral e três tipos de sucedâneo lácteo. Gomes \& Peixoto (1982) também não encontraram diferenças de ganho de peso de bezerros holandeses após o desaleitamento ( 6 a 16 semanas).

Azambuja (1980), no período de 6 a 16 semanas, obteve ganhos de peso diários em torno de $0,690 \mathrm{~kg}$ para os bezerros que ingeriram o leite integral e ganhos respectivos de 0,700 e $0,670 \mathrm{~kg}$ para os animais que receberam leite artificial com composição básica de 70 e $50 \%$ de leite condensado em pó acrescido de $20 \%$ de gordura suína.

Houve diferença significativa entre os tratamentos para altura na cernelha e perímetro torácico aos 90 dias de idade, de modo que aqueles que receberam o leite integral apresentaram médias superiores aos que consumiram o sucedâneo lácteo. Entretanto, Silva et al. (1987), na fase após o desaleitamento, não encontraram diferença significativa para altura de cernelha e perímetro torácico.

Após a retirada do leite integral, espera-se aumento no consumo de concentrado (Huber, 1977), como verificado neste experimento, contudo não houve diferença significativa quanto ao consumo $(\mathrm{P}=0,5624)$ entre as dietas líquidas.

Bezerros que receberam leite integral apresentaram, após o desaleitamento, melhor conversão alimentar aparente $(2,16)$ que os alimentados com sucedâneo lácteo com $10 \%(2,94), 15 \%(2,74)$ e $20 \%(2,91)$ de EE na matéria seca.

Durante o período experimental, o consumo de concentrado não apresentou diferença significativa $(\mathrm{P}=0,1811)$ entre as dietas líquidas, embora os animais alimentados com leite integral tenham consumido menos concentrado que aqueles que receberam o sucedâneo lácteo com $10 \%$ de extrato etéreo.

Segundo Gomes \& Peixoto (1982), o consumo médio diário de concentrado durante todo o período experimental foi menor para os animais que receberam o leite integral $(1,100 \mathrm{~kg})$, apesar de não ter diferido do tratamento composto por leite artificial com $70 \%$ de leite em pó desnatado $(1,170 \mathrm{~kg})$. O consumo de concentrado pelos bezerros que receberam o leite artificial constituído de $50 \%$ de leite desnatado em pó acrescido de $20 \%$ de extrato de soja e de $20 \%$ de gordura suína foi maior $(1,280 \mathrm{~kg})$, embora sem diferença significativa da dieta líquida com $70 \%$ de leite desnatado em pó.

A análise de regressão (Tabela 4) mostrou que $82 \%$ da variação do peso corporal aos 90 dias de idade $(\mathrm{P}=0,0002)$ resultou do acréscimo de gordura no sucedâneo lácteo $\mathrm{e}$ que $85 \%$ do ganho de peso corporal dos 57 aos 89 dias ( $\mathrm{P}=0,0011)$ foi ocasionado pelo consumo de concentrado na 
Tabela 4 - Equações de regressão de acordo com os tratamentos avaliados: leite integral e três níveis crescentes de extrato etéreo (10, 15 e $20 \%$ EE) no sucedâneo lácteo comercial

Table 4 - Regression equations for calves receiving whole milk or milk replacer with increasing ether extract levels (10, 15, and 20\% EE)

\begin{tabular}{|c|c|c|c|c|c|}
\hline \multirow[t]{2}{*}{$\begin{array}{l}\text { Período } \\
\text { Period }\end{array}$} & \multicolumn{4}{|c|}{$\begin{array}{l}\text { Tratamento } \\
\text { Treatment }\end{array}$} & \multirow[t]{2}{*}{$\begin{array}{l}\text { Equação de regressão } \\
\text { Regression equation }\end{array}$} \\
\hline & $\begin{array}{l}\text { Leite integral } \\
\text { Whole milk }\end{array}$ & $10 \%$ & $15 \%$ & $20 \%$ & \\
\hline $\begin{array}{l}\text { Peso ao } 56^{\mathrm{o}} \text { dia }(\mathrm{kg}) \\
\text { Weight at } 56^{\text {th }} \text { day }(\mathrm{kg})\end{array}$ & 50,05 & 48,47 & 43,73 & 44,28 & $\ddot{Y}=46,355$ \\
\hline $\begin{array}{l}\text { Peso ao } 90^{0} \text { dia }(\mathrm{kg}) \\
\text { Weight } 90^{\text {th }} \text { day }(\mathrm{kg})\end{array}$ & 75,74 & 66,90 & 62,70 & 62,55 & $\begin{array}{c}\ddot{Y}=60,58-4,76 \mathrm{Gba}+0,149 \mathrm{Gba}^{2}+0,681 \mathrm{Cc} 5789 \\
P=0,0001\end{array}$ \\
\hline $\begin{array}{l}\text { Ganho de peso médio diário } \\
80-56 \text { o dia }(\mathrm{kg} / \text { dia })\end{array}$ & 0,47 & 0,44 & 0,34 & 0,35 & $\ddot{Y}=0,336$ \\
\hline $\begin{array}{l}\text { Average daily gain } 8^{\text {th }}-56^{\text {th }} \text { day }(\mathrm{kg} / \text { day }) \\
\text { Ganho de peso médio diário } \\
570 \text { - }-89 \text { o dia }(\mathrm{kg} / \mathrm{dia}) \\
\text { Average daily gain } 57^{\text {th }}-89^{\text {th }} \text { day }(\mathrm{kg} / \text { day })\end{array}$ & y) & 0,48 & 0,43 & 0,43 & $\begin{array}{c}\ddot{\mathrm{Y}}=0,71-0,059 \mathrm{Gba}+0,001 \mathrm{Gba}^{2}-0,010 \mathrm{P} 8+ \\
0,008 \mathrm{CC} 57-89 \\
\mathrm{P}=0,0001\end{array}$ \\
\hline
\end{tabular}

Gba = gordura adicionada (Gba= added fat).

fase após o aleitamento, pela covariável (P8) e pelo acréscimo de gordura.

A quantidade de concentrado ingerida individualmente por dia, de acordo com a dieta líquida fornecida durante a fase de aleitamento, foi avaliada com o objetivo de determinar o efeito das dietas líquidas sobre o consumo de concentrado e a época de desaleitamento. Stumpf Jr. etal. (2000) recomendam como um dos critérios para determinar o momento do desaleitamento que animais da raça Jersey estejam consumindo de 0,400 a $0,500 \mathrm{~kg}$ de concentrado por dia.

Observou-se que os animais alimentados com o sucedâneo com 10\% EE atingiram o consumo mínimo de concentrado recomendado por Stumpf Jr. et al. (2000) entre o $22^{\circ}$ e $28^{\circ}$ dia de idade. Os demais bezerros que receberam sucedâneo atingiram a quantidade recomendada entre o 290 e 35 o dia de idade. Entretanto, os animais alimentados com leite integral apresentaram esse consumo entre o $43^{\text {o }}$ e 49으 dia de idade. Portanto, bezerros que receberam o sucedâneo tornaram-se mais cedo independentes da dieta líquida que os que receberam leite integral, permitindo melhor aproveitamento da dieta sólida. As médias diárias do consumo de concentrado, em kg de matéria seca, dos animais alimentados com as diferentes dietas líquidas, durante diferentes períodos da fase de aleitamento, são descritas na Tabela 5 .

As análises econômicas nas diferentes fases do experimento podem ser encontradas nas Tabelas 6, 7 e 8 .

$\mathrm{Na}$ fase de aleitamento, os bezerros que receberam o leite integral apresentaram custo total maior com alimentação que aqueles que receberam o sucedâneo. A relação custo/ganho de peso corporal foi melhor para os animais que ingeriram o sucedâneo com $10 \%$ de EE, com menor custo.
Tabela 5 - Valores médios diários por animal do consumo de concentrado comercial, em kg de matéria seca, no período de aleitamento de bezerros Jersey conforme a dieta líquida (leite integral, sucedâneo com $10 \% \mathrm{EE}$, sucedâneo com $15 \%$ EE e sucedâneo com $20 \%$ EE)

Table 5 - Average daily values of commercial concentrate intake, expressed as $\mathrm{kg}$ of dry matter, during pre-weaning period of Jersey calves, receiving liquid diets (whole milk, milk replacer with $10 \%$ EE, milk replacer with $15 \%$ EE and milk replacer with $20 \% E E)$

\begin{tabular}{|c|c|c|c|c|}
\hline $\begin{array}{l}\text { Dia } \\
\text { Day }\end{array}$ & $\begin{array}{l}\text { Leite integral } \\
\text { Whole milk }\end{array}$ & $10 \% \mathrm{EE}$ & $15 \% \mathrm{EE}$ & $20 \% \mathrm{EE}$ \\
\hline $\begin{array}{l}8^{o}-14^{0} \text { dia } \\
\text { Day } 8^{\text {th }}-14^{\text {th }}\end{array}$ & 0,04004 & 0,0938 & 0,0341 & 0,0345 \\
\hline $\begin{array}{l}15^{\circ}-21^{\circ} \text { dia } \\
\text { Day } 15^{t h}-21^{s t}\end{array}$ & 0,07784 & 0,2798 & 0,1377 & 0,1477 \\
\hline $\begin{array}{l}22^{\mathrm{o}}-28^{\mathrm{o}} \text { dia } \\
\text { Day } 22^{\text {th }}-28^{\text {th }}\end{array}$ & 0,12024 & 0,4427 & 0,3223 & 0,3175 \\
\hline $\begin{array}{l}290-35^{\circ} \text { dia } \\
\text { Day } 29^{\text {th }}-35^{\text {th }}\end{array}$ & 0,17297 & 0,6664 & 0,4677 & 0,4168 \\
\hline $\begin{array}{l}36^{\mathrm{o}}-42^{\mathrm{o}} \text { dia } \\
\text { Day } 36^{\text {th }}-42^{\text {nd }}\end{array}$ & 0,27749 & 0,7971 & 0,6156 & 0,6021 \\
\hline $\begin{array}{l}43^{\mathrm{o}}-49 \underline{\mathrm{o}} \text { dia } \\
\text { Day } 43^{r d}-49^{\text {th }}\end{array}$ & 0,44011 & 0,9653 & 0,7809 & 0,7645 \\
\hline $\begin{array}{l}50^{\mathrm{o}}-56^{\mathrm{o}} \mathrm{dia} \\
\text { Day } 50^{\text {th }}-56^{\text {th }}\end{array}$ & 0,72970 & 1,1520 & 0,9837 & 0,9404 \\
\hline
\end{tabular}

Após o desaleitamento e durante todo o período experimental, o valor gasto com alimentação dos bezerros criados com leite integral foi mais oneroso. Entretanto, durante todo o período experimental, a conversão alimentar aparente dos animais que receberam leite integral $(1,80 \%)$ foi melhor que a dos alimentados com sucedâneo lácteo com $10(2,52 \%), 15(2,52 \%)$ e $20 \%$ de EE na matéria seca (2,55\%), assim como o custo/kg, quando avaliado todo o período experimental. 
Tabela 6 - Quantidade utilizada dos alimentos e custo médio da dieta líquida e do concentrado durante a fase de aleitamento (8으 ao $56 \underline{0}$ dia) (valores em R\$ por bezerro em junho de 2003)

Table 6 - $\quad$ Amount of feed used and average cost of liquid diets and concentrate at pre weaning ( $8^{\text {th }}-56^{\text {th }}$ day) (values as $R \$$ by calves on June 2003)

\begin{tabular}{|c|c|c|c|c|c|c|c|c|}
\hline & \multicolumn{2}{|c|}{$\begin{array}{c}\text { Leite integral } \\
\text { Whole milk }\end{array}$} & \multicolumn{2}{|c|}{$10 \% \mathrm{EE}$} & \multicolumn{2}{|c|}{$15 \% \mathrm{EE}$} & \multicolumn{2}{|c|}{$20 \%$ EE } \\
\hline & L ou kg (\$) & $\mathrm{R} \$$ & $\mathrm{~kg}(\$)$ & $\mathrm{R} \$$ & $\mathrm{~kg}(\$)$ & $\mathrm{R} \$$ & $\mathrm{~kg}(\$)$ & $\mathrm{R} \$$ \\
\hline $\begin{array}{l}\text { Aleitamento } \\
\text { Pré weaning }\end{array}$ & & & & & & & & \\
\hline $\begin{array}{l}\text { Dieta líquida } \\
\text { Liquid diets }\end{array}$ & $147(0,45)$ & 66,15 & $14,70 \quad(2,00)$ & 29,40 & $14,70 \quad(2,00)$ & 29,40 & $14,70 \quad(2,00)$ & 29,40 \\
\hline Concentrado & $14,12(0,752)$ & 10,62 & $33,41(0,752)$ & 25,12 & $25,39(0,752)$ & 19,09 & $24,48(0,752)$ & 18,41 \\
\hline $\begin{array}{l}\text { Concentrate } \\
\text { Banha }\end{array}$ & & & $0,275(3,19)$ & 0,88 & $1,014(3,19)$ & 3,23 & $1,752(3,19)$ & 5,59 \\
\hline $\begin{array}{l}\text { Lard } \\
\text { Custo total } \\
\text { Total cost }\end{array}$ & & 76,77 & & 55,40 & & 51,72 & & 53,40 \\
\hline $\begin{array}{l}\text { Ganho peso } \\
\text { Gain weight }\end{array}$ & 23,55 & & 20,42 & & 16,13 & & 16,58 & \\
\hline $\begin{array}{l}\text { Custo/kg peso } \\
\text { Cost/kg weight }\end{array}$ & & 3,26 & & 2,71 & & 3,21 & & 3,22 \\
\hline
\end{tabular}

Tabela 7 - Quantidade utilizada dos alimentos e custo médio da dieta líquida e do concentrado durante a fase desaleitamento (570 ao 89o dia) (valores em R\$ por bezerro em junho de 2003)

Table 7 - $\quad$ Feed amount and average cost of liquid diets and concentrate at weaning period (57th $-89^{\text {th }}$ day) (values in $R \$$ per calf on June 2003)

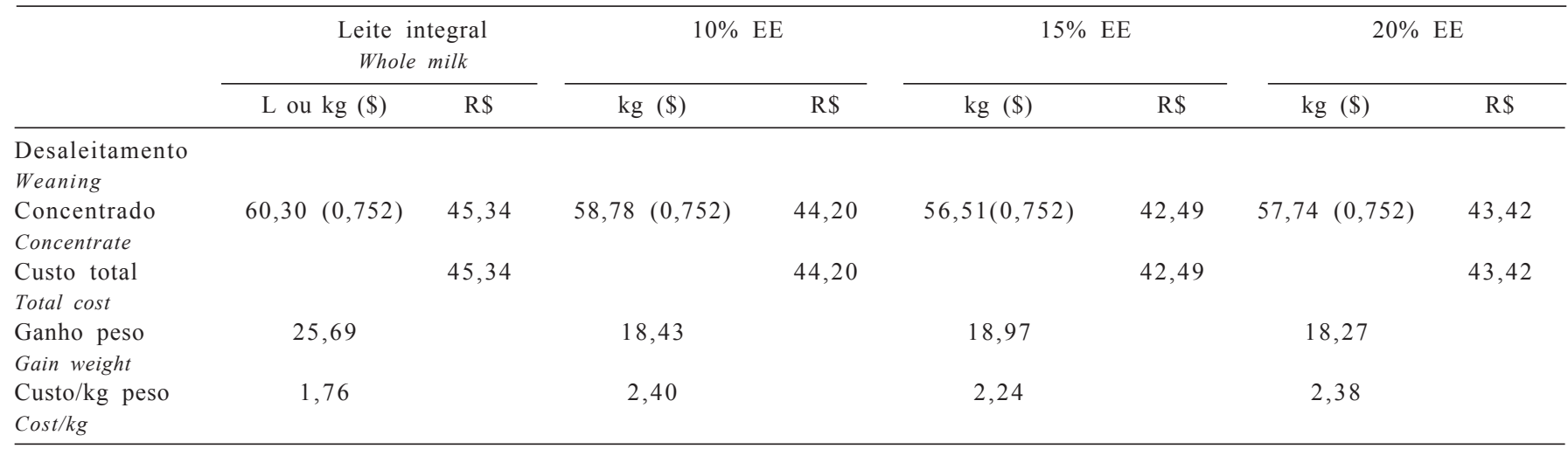

Tabela 8 - Quantidade utilizada dos alimentos e custo médio da dieta líquida e do concentrado durante o período total do experimento ( 8 o ao 89 o dia) (valores em $\mathrm{R} \$$ por bezerro em junho de 2003)

Table 8 - $\quad$ Feed amount and average cost of liquid diets and concentrate during total period ( $8^{\text {th }}-89^{\text {th }}$ day) (values in $R \$$ per calf on June 2003)

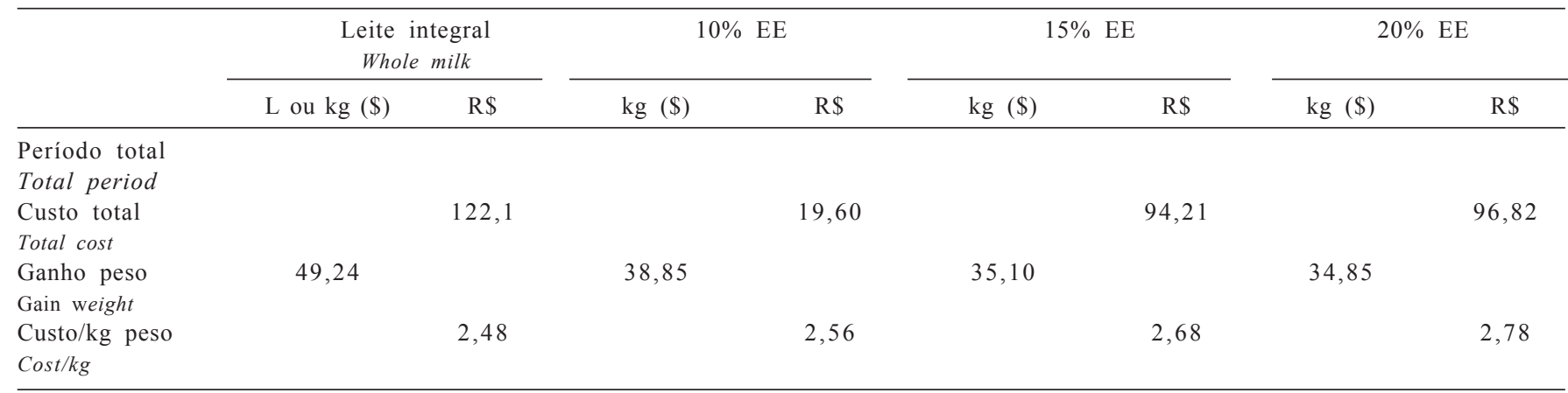




\section{Conclusões}

O sucedâneo lácteo com $10 \%$ de extrato etéreo, fornecido durante a fase de aleitamento, proporcionou ganho de peso corporal superior à dieta líquida com 15 e $20 \%$ de EE. Também promoveu a melhor relação custo com a alimentação (dieta líquida e o concentrado):ganho de peso corporal, se comparado aos demais tratamentos.

\section{Agradecimento}

À Universidade Federal de Pelotas(UFPEL), Faculdade de Agronomia Eliseu Maciel, pela oportunidade da realização deste curso de mestrado.

À AVIPAL, pela doação do sucedâneo lácteo Terneleite.

À Capes (Coordenação de Aperfeiçoamento de Pessoal de Nível Superior), pela bolsa concedida no decorrer do curso.

À EMBRAPA-CPACT (convênio UFPEL/EMBRAPA), que permitiu a utilização da infra-estrutura e dos animais para a realização deste experimento.

Ao professor (UFPEL/DZ)Werner Erwin Lüder, pelos conselhos e pelas discussõeses.

\section{Literatura Citada}

ALVAREZ, J.C.; LUCCI, C.S.; MELLOTT, L. 1999. Concentrado protéico de soja como substituto parcial da proteína láctea em sucedâneos do leite para bezerros. Disponível em: <http://www.scielo.br Acesso em: 03/06/2005.

AZAMBUJA, V.E.R. Estudo de dietas líquidas artificiais e o valor comparativo entre o sorgo e o milho, na alimentação de terneiros da raça Holandesa, desaleitamento precoce. Pelotas: Universidade Federal de Pelotas, 1980. 103p. Dissertação (Mestrado em Zootecnia) - Universidade Federal de Pelotas, 1980.

BANYS, V.L.; PAIVA, P.CA.; LOZANO, D.M. et al. Medidas barimétricas de bezerros provenientes do aleitamento com sucedâneos baseados em proteína texturizada de soja e diferentes fontes de lactose. In: REUNIÃO ANUAL DA SOCIEDADE BRASILEIRA DE ZOOTECNIA, 36., 1999, Porto Alegre. Anais... São Paulo: Gmosis, 1999, CD-ROM. Nutrição de Ruminantes. Avaliação com animais. NUR-023.

BITTENCOURT, D.; STUMPF, W.J.; XAVIER, S.S. et al. A importância da atividade leiteira na economia agropecuária do RGS. In: STUMPF, W.J.; BITTENCOURT, D.; GOMES, J.F. et al. (Eds.) Sistemas de pecuária de leite: uma visão na região de clima temperado. 1.ed. Pelotas: Embrapa Clima Temperado, 2000. 195p.

BYERS, F.M.; SCHELLING G.T. Los lipidos en la nutricion de los rumiantes. In: CHURCH, D.C. (Ed.) El ruminante fisiología digestiva y nutrición. Zaragoza: Acribia, 1993. p.339-356.

CAMPOS, O.F. 2005. Criação de bezerras de raças leiteiras. Disponível em: http://www.tecnologiaetreinamento.com.br/ Acesso em: 01/06/2005.

CAMPOS, O.F.; HUBER, J.T.; BERGEN, W.G. Partial substitution of milk protein with spray-dried fish solubles or soy protein concentrate in calf milk replacers. In: ANNUAL MEETING OF THE AMERICAN DAIRY SCIENCE ASSOCIATION, 76., 1981, Baton Rouge. Proceedings... Champaign: American Dairy Science Association, 1981. v.1, p.125.
COSTELLO, R. 2005. Merrck's calf milk replacer guide. Disponível em: http://merricks.com/tech_milkreplacerguide.htm> Acesso em: 02/06/2005.

COVERDALE, J. 2005. Baby it's cold outside - Feeding calves this winter Disponível em: http://www.ces.uga.edu/Agriculture/ asdsvm/dairyscience Acesso em: 02/06/2005.

DAIRY CONNECTION. 1998. Calf management: supplemental fat in liquid for calves. Disponível em: http:// www.ag.ndsu.nodak.edu Acesso em: 03/06/2005.

DRACKLEY, J.K.; RUPPERT, L.D.; ELLIOTT, J.P. et al. 2002. Effects of increased solids intake on growth and physiological responses of Jersey calves housed in hutches during winter. Disponível em: http://traill.outreach.uiuc.edu Acesso em: 20/11/2002.

FERREIRA, M.A.; CASTRO, A.C.G.; SILVA, J.F.C. et al. Sistemas de aleitamento de bezerros. 2. Desempenho dos bezerros. Revista da Sociedade Brasileira de Zootecnia, v.25, n.4, p.729-740, 1996.

GOMES, I.P.O.; PEIXOTO, R.R. Extrato de soja e gordura de frango em dietas líquidas artificiais e farelo de arroz desengordurado na alimentação de terneiros desaleitados precocemente. Revista da Sociedade Brasileira de Zootecnia, v.11, n.1, p.24-37, 1982.

HEINRICHS, A.J.; HARGROVE, G.L. Standards of weight and height for Guersey and Jersey heifers. Journal of Dairy Science, v.74, n.5, p.1684-1689, 1991.

HILL T.M.; ALDRICH, J.M.; PROESCHEL et al. 2002. Feeding neonatal calves milk replacers with different protein, fat, and lactose levels. Disponível em: http://www.adsa.org/ jds/2002abs/jnabs17.pdf. Acesso em: 01/06/2005.

HOLSTEIN FOUNDATION. 2003. World of dairy cattle. Disponível em: http://www.holsteinfoundation.org. Acesso em: 05/06/2005.

HUBER, J.T. Nutrição de bovinos jovens. In: SIMPÓSIO SOBRE NUTRIÇÃO DE BOVINOS, 1977, Piracicaba. Anais... Piracicaba: Fundação de Estudos Agrários Luiz de Queiroz, 1977. 88p.

HUTJENS, M.F. 2002. Dairy calf nutrition and management Disponível em: http://www.inform.umd.edu. Acesso em: 20/10/ 2002.

JASTER, E.H.; McCOY, G.C.; FERNANDO, R.L. Dairy fat in milk or milk replacers for dairy calves raised in hutches during the winter. Journal of Dairy Science, v.73, n.7, p.1843-1850, 1990 .

JASTER, E.H.; McCOY, G.C.; SPANSKI, N. Effect of extra energy as fat or milk replacer solids in diets of young dairy calves on growth during cold weather. Journal of Dairy Science, v.75, n.9, p.2524-2531, 1992.

KUEHN, C.S.; OTTERBY, D.E.; LINN, J.G. The effect of dietary energy concentration on calf performance. Journal of Dairy Science, v.77, n.9, p.2621-2629, 1994.

LUCCI, C. Bovinos leiteiros jovens. São Paulo: Nobel, 1989. $371 \mathrm{p}$.

MATOS, L.L.; CAMPOS, O.F.; PIRES, M.F.A. et al. Comparação entre o leite integral e diferentes sucedâneos do leite na alimentação de bezerros. Revista da Sociedade Brasileira de Zootecnia, v.13, n.4, p.447-452, 1984.

MEDINA, R.B.; LUDER, W.E.; FISCHER, V. et al. Desaleitamento precoce de terneiros da raça Holandês preto e branco utilizando sucedâneo do leite e concentrado farelado ou peletizado. Revista Brasileira de Agrociência, v. 8, n.1, p.61-66, 2002.

O`BRIEN, M.L.; TOUCheTTE, K.J.; COAlson, J.A. et al. Inclusion of vegetable fats in calf milk replacers. Journal of Dairy Science, v.86, n.85, p.21, 2003 (suppl.).

PEIXOTO, R.R. Valor da dieta líquida artificial na alimentação de terneiros desaleitados precocemente nas condições do sul do Brasil. Revista da Sociedade Brasileira de Zootecnia, v.11, n.2, p.281-288, 1982 .

PRADO, I.N.; TIESENHAUNER, I.M.E.V.V. Desaleitamento precoce de bezerros. sucedâneos a base de "leite de soja" e gordura de porco. In: REUNIÃO ANUAL DA SOCIEDADE BRASILEIRA DE ZOOTECNIA, 19., 1982, Piracicaba. Anais... Piracicaba: Sociedade Brasileira de Zootecnia, 1982. p.147-148. 
QUIGLEY, J. 2001. Fat levels in milk replacers...Calf Notes $\mathbf{n}^{\circ} 44$ Disponível em: www.calfnotes.com Acesso em: 01/06/2005.

ROY, J.H.B. El ternero nutricion y patologia. Zaragoza: Acribia, 1972. v.2, $199 \mathrm{p}$

STATISTICAL ANALYSES SYSTEM - SAS. SAS/STAT user's guide. version 6.12 4.ed. Cary: 1989.

SILVA, A.G.; FARIA, V.P.; GODÓI, C.R.M. Efeitos da substituição da gordura do leite por gordura de soja no crescimento de bezerros. Pesquisa Agropecuária Brasileira, n.12 (único), p.233-240, 1977.

SILVA, M.M.L.; VIEIRA, P.F.; TOSI, H. et al. Utilização de substituto do leite integral no alimento de bezerros de raças leiteiras em sistema de desaleitamento precoce. Revista da Sociedade Brasileira de Zootecnia, v.16, n.3, p.215-221, 1987.

STUMPF, W.J.; BITTENCOURT, D.; GOMES, J.F. et al. Sistema de produção. In: STUMPF, W.J.; BITTENCOURT, D.; GOMES, J.F. et al. (Eds.) Sistemas de pecuária de leite: uma visão na região de clima temperado. 1.ed. Pelotas: Embrapa Clima Temperado, 2000. 195p.

SUSIN, I.; NETO, R.M.; PIRES, A.V. et al. Desempenho de bezerros submetidos a diferentes dietas líquidas e períodos de aleitamento. Revista da Sociedade Brasileira de Zootecnia, v.17, n.1, p.108-114, 1988 .
TIKOFSKY, J.N.; AMBURGH, M.E.; ROSS, D.A. Effect of carbohydrate and fat content of milk replacer on body composition of Holstein bull calves. Journal of Animal Science, v.79, p.2260-2267, 2001.

VASCONCELOS, A.M.; FAÇANHA, D.A.E.; OLIVO, C.J. et al. Desempenho de bezerros da raça Holandesa submetidos a diferentes dietas líquidas e instalações. In: REUNIÃO ANUAL DA SOCIEDADE BRASILEIRA DE ZOOTECNIA, 35., 1998 , Botucatu. Anais... Piracicaba: Sociedade Brasileira de Zootecnia, 1998. p.68-70

WIJAYASINGHE, M.S.; SMITH, N.E.; BALDWIN, R.L. Growth, health, and blood glucose concentrations of calves fed highglucose or higt-fat milk replacer. Journal of Dairy Science, v.67, n.12, p.2949-2956, 1984.

Recebido: 10/11/04 Aprovado:08/08/05 